\title{
Bilateral paramedian thalamic artery infarcts: report of eight cases
}

\author{
MASSIMO GENTILINI, ENNIO DE RENZI, GIROLAMO CRISI* \\ From the Departments of Neurology and Radiology, ${ }^{*}$ University of Modena, Italy
}

SUMMARY Eight consecutive patients with CT scan evidence of a bilateral infarct in the territory of the paramedian thalamic artery are reported. In seven cases the infarct also extended to the territory of the polar artery. The main symptoms were: (1) disorder of vigilance which cleared in a few days, and hypersomnolence which lasted longer and in two patients was still present a year later; (2) amnesia, detectable clinically in four patients and only with tests in two patients, which persisted in one patient for three years; (3) changes of mood and bulimia present in five and four patients respectively; and (4) vertical gaze paresis in five patients. Only one patient died, and in the remainder the symptoms tended to subside, but none of the patients who could be followed-up for a year returned to normal behaviour. Clinical and CT scan correlations pointed to the mammillo-thalamic tract as the structure whose damage was responsible for the memory disorders.

Before computed tomography (CT) infarct of the thalamus was a diagnosis that the clinician could at most suspect, when confronted with a clinical picture resembling the classical Dejerine-Roussy's syndrome ${ }^{1}$ but not substantiate in the absence of verification by necropsy. Even more difficult and tentative was the recognition of the other topographical thalamic syndromes that had been reported. ${ }^{2}$ CT scan has greatly improved our ability to identify in vivo discrete syndromes corresponding to the involvement of the territories supplied by the thalamic arteries. Based on the anatomical description provided by Percheron $^{3-5}$ the following types have been identified: $^{6}(1)$ antero-lateral infarct, associated with polar artery occlusion; (2) postero-lateral infarct, associated with geniculo-thalamic artery occlusion; (3) infero-median infarct, associated with paramedian artery occlusion; and (4) infarct involving the globus pallidus, the posterior limb of the internal capsule and the lateral thalamic nuclei, associated with anterior choroidal artery occlusion.

Address for reprint requests: Dr Ennio De Renzi, Clinica Neurologica, Via del Pozzo, 71, I-41100-Modena, Italy.

Received 3 June 1986 and in revised form 28 October 1986. Accepted 6 November 1986
A well-defined clinical picture is represented by the bilateral infarct of the paramedian artery. This is not a rare event since the vessels of both sides can originate from a common trunk. The area of distribution of the paramedian artery presents with anatomical variations from subject to subject, also, because it not rarely supplies the territory of an absent polar artery, and may be associated with the occlusion of the paramedian mesencephalic artery. The area includes ${ }^{4}$ the nucleus parafascicularis, the habenularintrapeduncular tract (Meynert's retroflex bundle), the antero-medial portion of the centromedian nucleus, the internal medullary lamina, the ventrooral-medial nucleus and it may reach the mammillothalamic tract anteriorly. If the infarct extends to the territory of the polar artery, the lesion involves the anterior part of the ventral thalamus and, in particular, encroaches upon the ventral pole of the mediodorsal nucleus, the ventral part of internal medullary lamina and part of the mammillo-thalamic tract. $^{7}$

In this paper we report the clinical and CT scan findings of eight consecutive patients, seen in our department for a bilateral thalamic infarct in the territory of the paramedian artery, which in most cases also extended to the territory of the polar artery. 


\section{Case reports}

Case 1 This 66 year old right-handed man was accustomed to take meals at his sister's house, since his wife's death 14 years earlier. One day he was particularly late to lunch and his sister telephoned him. The patient was surprised at her request, because, he said, "it is just 6 am and this is not lunch time." When he eventually came, his sister was amazed at hearing him speak about his wife as if she were still living with him. In the following days it was apparent that he did not know where he was and mistook day for night. On admission, the only neurological sign was a vertical gaze paresis, involving all kinds of movements in the downward direction and sparing the oculo-cephalic reflex in the upward gaze. The patient was alert, cooperative, and cheerful, but had no clear idea of why he had been hospitalised. He correctly reported basic biographical data, had normal language comprehension and expression and could make simple calculations, but his memory for both anterograde and retrograde events was poor. If not stimulated, he tended to sleep most of the day; yet, when awakened, he quickly answered questions. His thought content revealed a mixture of confabulation and delusions of grandeur. He claimed to live with a woman, sometimes identified as his dead wife, sometimes as a woman in all respects identical to her but whom he had just married, and sometimes as his wife's sister (who had never existed). He also claimed that he was very rich, owning eight flats, and had a large Swiss bank account. He said that he could speak many foreign languages and was a general in the Air Force. He offered a large sum to a nurse if she would agree "to come with me under the blankets, where nobody will see us." The symptomatology remained unchanged for the month during which he was hospitalised. A few days after he had returned home, he went to the police station asking why his wife had abandoned him.

At the follow-up, 7 months later, he appeared cheerful and a bit garrulous, but perfectly oriented to time, place and person. He admitted that his wife was dead, and said that, after having lived for several years with her cousin, he now remained alone and was looking for a young girl who, enticed by his wealth, would be willing to marry him. He was well-informed on current events and showed no sign of memory deficit, but was still impaired on formal memory testing (table 1). Vertical gaze paresis had improved.

Case 2 This 47 year old woman suddenly complained of dizziness and fell to the ground, unable to answer any questions. Taken to the emergency department of our hospital, she appeared drowsy and did not speak spontaneously, but reacted to painful stimuli and was able to obey elementary commands. Three days later she was admitted to the neurological ward. She was sleepy throughout the day, though frequently tossing in bed. When seated, she tended to fall forward or to the side. She correctly answered simple questions in a whisper and with a few words, but never took the initiative to speak. A limitation of upwards saccadic and pursuit eye movements was observed, while downwards, lateral and convergence movements were normal. Relatives noticed that during the first 3 days of disease the patient voraciously ate whatever was offered to her. In the following 2 weeks drowsiness alternated with restlessness and a certain degree of aggressiveness: she accused doctors of trying to kill her, kicked out in bed and laughed coarsely. The behaviour slowly improved, but was still childish and euphoric a month later, when she was discharged. No retrograde amnesia was observed, but her performance on verbal learning memory tasks was poor (table 1), possibly due to difficulties in concentrating.

At follow-up 18 months later, upward gaze paresis was still present and her husband reported that the patient passed most of the day in bed, sleeping much more than usual. However, when awake, she looked at television and read newspapers. She showed abnormal irritability. No memory deficit was observed. She was still hyperphagic and had increased $15 \mathrm{~kg}$ in weight. In the following months, she fell into a depressive state, with feelings of guilt and worthlessness, which required admission to a psychiatric ward. She improved after amitriptyline treatment.

Case 3 This 35 year old man was, on awakening, unable to answer simple questions, apathetic and sleepy. Admitted to another hospital, he remained drowsy and speechless for a few days; when he began speaking again, he was grossly disoriented to time and place and forgetful of past and present events. He ate and drank voraciously and indiscriminately, without becoming satiated, and was hyper-

Table 1 Intelligence and memory test scores

\begin{tabular}{|c|c|c|c|c|c|c|}
\hline$N$ & $P I Q$ & $V I Q$ & $I Q$ & $\begin{array}{l}\text { Story } \\
(15 \cdot 76)^{*}\end{array}$ & $\begin{array}{l}\text { Word list } \\
(6 \cdot 58)^{*}\end{array}$ & $\begin{array}{l}\text { Paired associates } \\
(8 \cdot 73)^{*}\end{array}$ \\
\hline $\begin{array}{l}1(a) \\
\text { (b) } \\
2 \\
3 \\
4(a) \\
\text { (b) } \\
5 \\
6 \\
7 \\
8(a) \\
\text { (b) }\end{array}$ & $\begin{array}{c}82 \\
88 \\
92 \\
99 \\
75 \\
92 \\
- \\
- \\
112 \\
58 \\
93\end{array}$ & $\begin{array}{r}106 \\
100 \\
98 \\
107 \\
71 \\
103 \\
- \\
88 \\
119 \\
94 \\
108\end{array}$ & $\begin{array}{r}94 \\
94 \\
95 \\
103 \\
73 \\
98 \\
- \\
- \\
115 \\
76 \\
101\end{array}$ & $\begin{array}{r}5.88 \\
8.88 \\
17.92 \\
5.93 \\
9.09 \\
8.03 \\
-5.59 \\
3.09 \\
14.95 \\
21.00\end{array}$ & $\begin{array}{l}4.97 \\
5 \cdot 57 \\
7.26 \\
5.60 \\
3.45 \\
8.48 \\
- \\
3.36 \\
5.94 \\
5 \cdot 20 \\
8 \cdot 28\end{array}$ & $\begin{array}{r}6.89 \\
3.39 \\
16.54 \\
3.32 \\
1.00 \\
18.58 \\
3 \cdot 18 \\
4.66 \\
10.25 \\
15.66\end{array}$ \\
\hline
\end{tabular}

The second examination of Patients 1,4 and 8 was carried out approximately three months later.

*Cut-off for normal performance. 
somnolent and irritable. These symptoms lasted for 2 months. When admitted to our department, 3 months postonset, his behaviour was normal, except for a severe retrograde and anterograde amnesia, which was still present on follow-up, 3 years later. He was very inaccurate about events and persons in Italian public life in the last 5 years and was unable to learn new information. No gaze disorder was ever observed.

Case 4 This 53 year old man suddenly lost consciousness, and fell to the ground. He recovered in a few minutes, but in the subsequent hours his level of consciousness waxed and waned, oscillating from being able to answer simple questions to total unresponsiveness. Admitted to the ward, he remained confused and sleepy for 6 days. When he became more alert and examinable, a vertical gaze paresis for both upwards and downwards voluntary and pursuit movements could be shown. A striking bulimia (to the point that the patient stole room-mates' food) persisted for 20 days. He complained of weakness and sleepiness, showed a marked irritability and was prone to pity himself and weep. No memory deficit was clinically evident, though his performance on memory tests was poor (table 1).

On follow-up examination 2 years later, he complained of falling asleep during the day if he was not engaged in some activity. His mood had progressively returned to normal and he took great interest in sport news, which he correctly reported. His performance on memory tests was practically normal. Vertical gaze paresis was unchanged.

Case 5 This 70 year old woman with a 15 year history of hypertension fell into a diencephalic coma which lasted 2 days. This was progressively followed by a state of fluctuating vigilance in which periods of marked somnolence alternated with periods in which she could answer simple questions with a slurred speech. Memory could not be tested, but orientation to time and space was faulty. No gaze movements on the vertical plane could be elicited. The patient died 17 days after the onset of disease.

Case 6 This 58 year old man with a long history of alcoholism was admitted to the Internal Medicine Department because of liver disorders. The consultant neurologist found him to be alert and cooperative with gait disorder, incoordination on the finger to nose and heel to knee tests, and with a mild peripheral paresis of the lower limbs with absence of tendon reflexes but no sensory deficits. Ocular movements were fuli. A few days later the patient suddenly began stuttering. The symptom lasted for a week and then subsided completely. A CT scan was performed and it unexpectedly showed a bilateral paramedian thalamic infarct. A thorough neurological examination was again carried out, but no new neurological and neuropsychological deficit was found except for a mild memory impairment, only apparent on formal testing (table 1) and of which he had been aware long before.

At follow-up, a year later, relatives reported that the patient slept until $11 \mathrm{am}$. It is, however, uncertain whether this behaviour was pathological, since he was practically bedridden due to cerebellar gait disorders, and did not commit himself to any activity. In all other respects he appeared normal.

Case 7 This 73 year old man suddenly complained for 10 minutes of blurring of vision. The next day his wife noticed that he continuously repeated the same question, forgetting the answer. He also reported events of the recent past that had never happened. Admitted to the ward, neurological examination was unremarkable. Vertical gaze was full. The patient was alert and cooperative and never showed a tendency to daytime sleeping. He had, however, a profound memory disorder for recent and past events and showed a marked tendency to confabulate. Occasionally he lost his temper over trivial events and performed strange acts. Once he urinated in a basin and then poured the urine into a bottle of water, justifying his behaviour by saying that he had been requested to keep his urine for examination. In the subsequent days his behaviour cleared, but amnesia persisted for the month during which he was hospitalised. He was not available for follow-up.

Case 8 This 32 year old woman was a heavy smoker and had been taking the pill for 3 months. She was found, upon awakening, in a drowsy state and confabulating about the events of the previous day. The patient was first admitted to a neurosurgical unit. She was uncooperative, spoke in an incoherent way and was sleepy most of the time, but, when awake, had periods of unrest during which she kept on scratching her breast. A subarachnoid haemorrhage was suspected but not confirmed by a CT scan and lumbar puncture. Two weeks later she was transferred to our department. Neurological examination showed a left hemianopia, more dense in the upper quadrant, right Babinski's sign, incoordination of right limb movements, nystagmus in the lateral gaze position and vertical paresis of saccadic and pursuit movements with preserved oculocephalic reflexes. A mild exophthalmus and midriasis were apparent in the left eye. She was still disoriented to space and time, hallucinated and often failed to answer simple questions. She claimed to be 23 years old, to be unmarried and to have no children (she had two) and addressed her husband incorrectly. Language and praxis were unaffected, but she was dysarthric and often spoke in a whisper.

A second CT scan, performed 3 weeks after the stroke, showed bilateral, symmetric infarcts of the medial thalamichypothalamic region. In addition, there was an infarct in the calcarine territory of the right posterior cerebral artery, which was responsible for her left hemianopia. For the remainder of her hospitalisation, which lasted a month, only a minor improvement in her clinical picture was observed. She remained disoriented, hallucinated and when requested to report family events, she was frequently mixed up. Her mood was fickle, showing a tendency to rapidly pass from childish and euphoric manifestations to outbursts of crying and depression. She was amnesic about recent events, but past memory was preserved.

Follow-up examination three and a half months after onset showed a substantial improvement of cognitive functions, which was confirmed by formal testing (table 1), but a remarkable deficit of drive and motivation. She was reported by her relatives to be apathetic and idle, to pass most of her time lying down on a sofa watching animated cartoons on TV, and to take no interest in housekeeping. If rebuked for her laziness, she burst into tears, but rapidly fell again into her inert state. She was oriented to space and time, gave sensible answers to common questions and was able, if urged, to do housework, but spontaneously took no initiative. She had only partial insight into the abnormality of her behaviour. Her mother remarked that she would keep on 
Table 2 Summary of symptoms presented by the patients

\begin{tabular}{|c|c|c|c|c|c|c|c|c|}
\hline & 1 & 2 & 3 & 4 & 5 & 6 & 7 & 8 \\
\hline Coma & - & + & - & + & + & - & - & - \\
\hline Confusion & + & + & + & + & + & - & + & + \\
\hline Hypersomnia & + & + & + & + & + & - & - & + \\
\hline Amnesia & + & - & + & $(+)$ & $?$ & $(+)$ & + & + \\
\hline Confabulation & + & - & - & - & - & - & + & + \\
\hline Mood disorders & - & + & + & + & - & - & + & + \\
\hline Bulimia & - & + & + & + & - & - & - & + \\
\hline Vertical gaze palsy & + & + & - & + & + & - & - & + \\
\hline
\end{tabular}

+ and - indicate presence or absence of the symptom; $(+)=$ amnesia detectable only with formal test examination; ? = not testable.

eating food which was offered to her, without giving signs of satiety, but did not ask for it, if it was not present. The left hemianopia was unchanged, and the vertical movement paresis had only slightly improved.

\section{Neuropsychological examination}

All patients, with the exception of Patient 5, who died before testing was possible, were given the WAIS and 3 tests of verbal memory about 15 days after onset. The memory tests included immediate and delayed recall of a story, learning a 10 word list and 10 verbal paired-associates. For each test a score discriminating normal from pathological performance has been derived from the administration to 100 normal and 20 amnesic patients. ${ }^{8}$ Table 1 reports the scores achieved by the patients.

IQ was in the normal range in all patients except Patients 4 and 8 . These patients were impaired on the first examination, which was carried out 20 days after the stroke and when they were still hypersomnolent; both obtained normal scores when retested 3 months after onset. Only Patient 2 had normal scores on the memory tests. The other six patients were markedly impaired when first examined. Patients 1, 4 and 8 were again tested approximately 3 months after onset: the first still performed poorly on all three tests, the second on story recall only, the third had completely recovered.

Table 2 summarises the neurological findings found in the patients.

\section{CT scan findings}

CT was carried out 4 days to 3 months after stroke. In Patients 1, 2, 4, 6 and 8 it was performed after intravenous administration of contrast medium. It showed a bilateral infarct in the territory of the paramedian artery in all cases. However, the infarct area was confined to this territory in only one case (No. 3), while it involved the nuclei supplied by both the paramedian and the polar arteries in all other patients. The extension of the infarct to the territory of the polar artery was bilateral in three cases (Nos. 4, 5 and 7) and unilateral in four cases (Nos. 1, 2, 6 and 8). The whole hypothalamus-thalamic region was covered by thin CT sections of $6 \mathrm{~mm}$ each, corresponding to the area from section Hd -0.5 to +9.5 (Plates 51-54) of the Atlas of Schaltenbrand and Wahren. ${ }^{9}$

Figure 1 ( $a$ to $h$ ) shows the CT scan slice of each patient in which the infarct was more evident. It corresponds to the section Hd +4.0 of the Atlas, except for Patient 3 in whom it refers to section $\mathrm{Hd}+0 \cdot 5$. Figure $2(\mathrm{a}$ and $\mathrm{b})$ shows the Atlas maps of sections $\mathrm{Hd}+4 \cdot 0$ and +0.5 . Table 3 summarises the structures involved by the lesion, as displayed by CT scan.

The bulk of the infarct involved the midline nuclei, the lateropolar nucleus, the ventro-oralis part of the ventrolateral nucleus, the mammillo-thalamic tract, the internal medullary lamina and the ventrobasal part of the mediodorsal nucleus.

\section{Discussion}

There are reports in the literature of $\mathbf{4 0}$ cases of bilateral paramedian thalamic infarction, documented by necropsy or CT scan: besides those reviewed by Castaigne $e a^{10}$ an additional 27 have appeared in the recent literature. ${ }^{6711-22}$ By far the largest series is that of Castaigne et al, ${ }^{10}$ who reported five personal cases with paramedian thalamic infarct and 13 with thalamic-peduncular infarct, verified at necropsy. Although necropsy studies are undoubtedly superior to CT scan studies in terms of accuracy and reliability of lesion assessment, the very fact that they are based on patients who died leads to a biased representation of the clinical picture, which can be better derived from a consecutive series of patients diagnosed on the basis of the CT scan.

The symptomatology is rather stereotyped and essentially consists of the following four elements:

1. Disorders of vigilance Stupor or coma of a diencephalic type marked the onset of disease in three patients (Nos. 2, 4 and 5). This was always associated with vertical gaze paresis and lasted from a few hours to 5 days, giving way progressively to a confusional state. Disorientation to place and time was also apparent in patients who did not lose consciousness, except Patient 6 whose symptoms were amazingly minor. Confusion eventually cleared, while hypersomnia, which was remarkable in six patients, lasted for weeks or months, with two patients (Nos. 2 and 4) still being hypersomnolent and bedridden for most of 


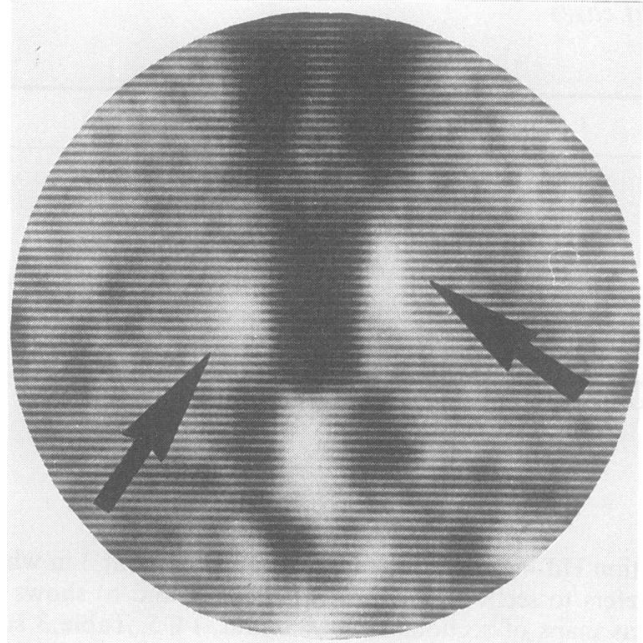

(a)

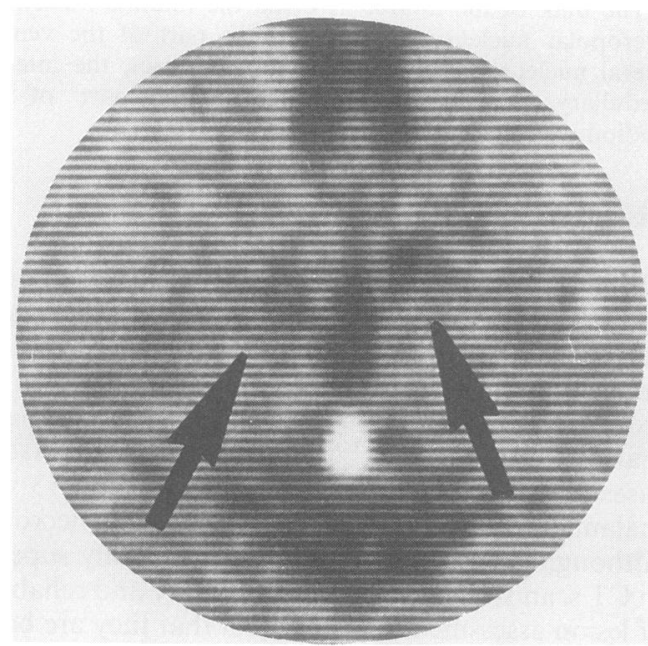

(c)

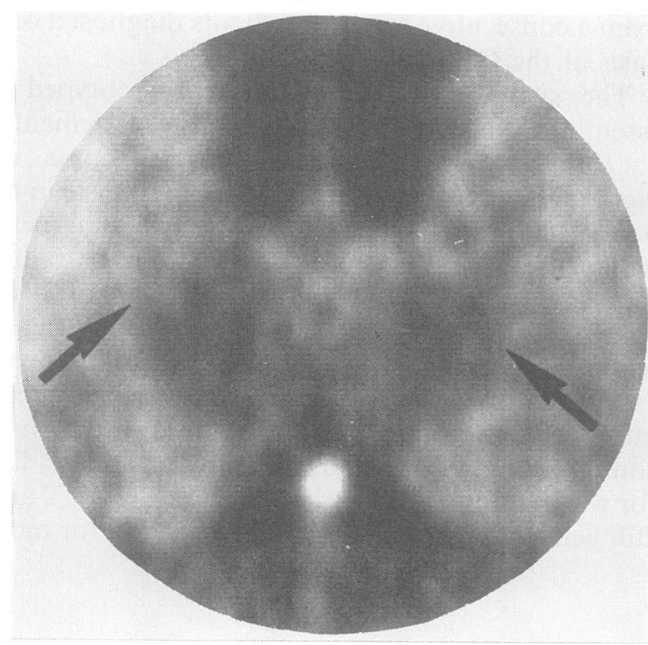

(e)

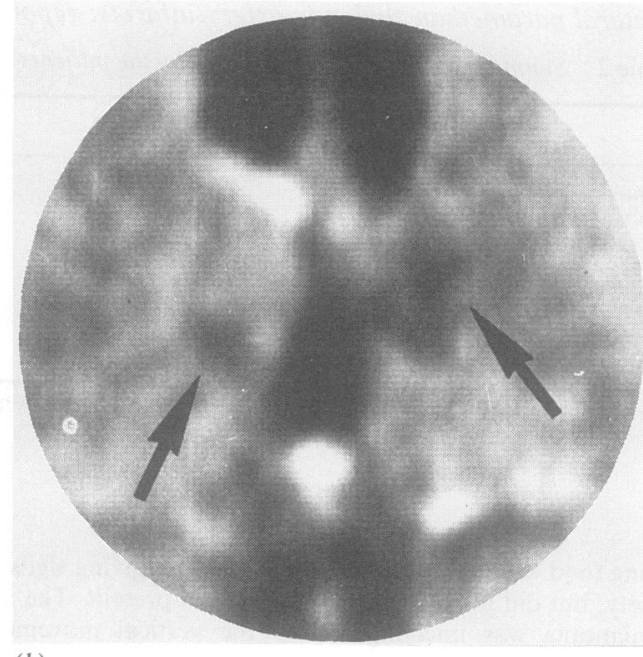

(b)

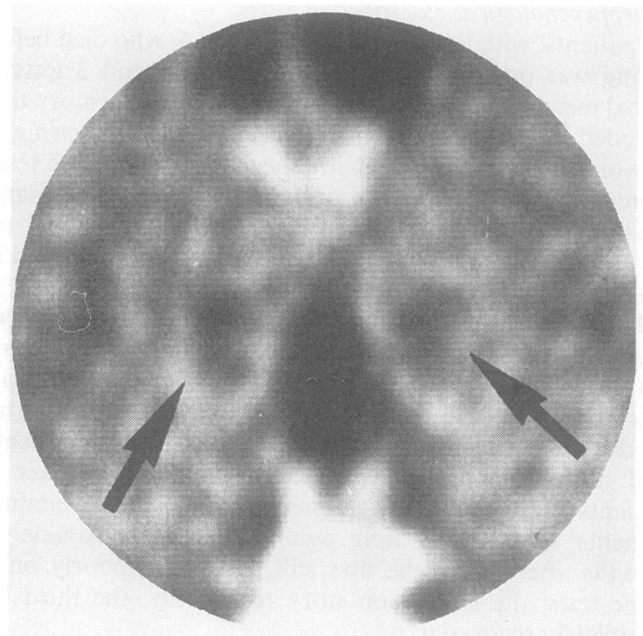

(d)

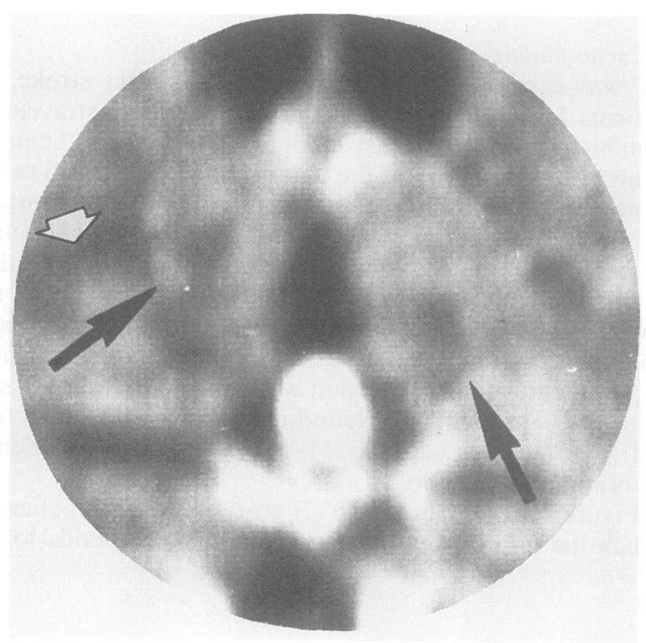

(f) 


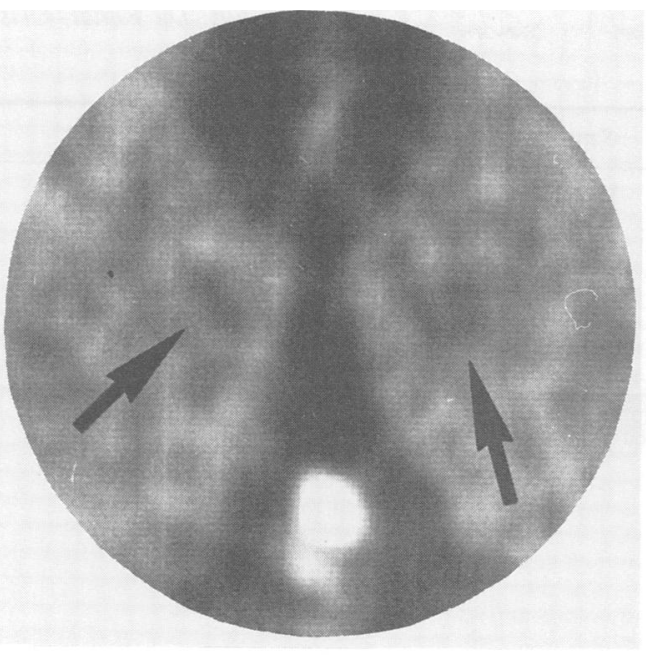

(g)

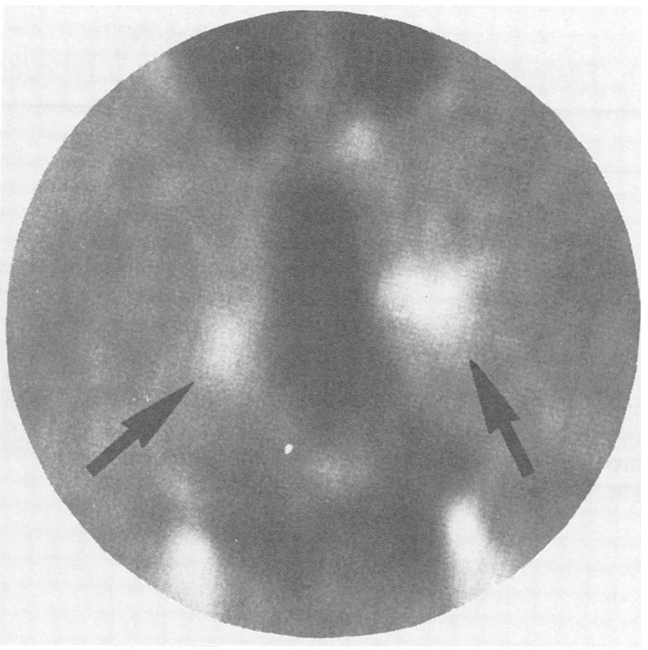

(h)

Fig 1 CT scans of the eight patients ( $a$ to $h$ ) taken at approximately $43 \mathrm{~mm}$ above the canthomeatal line at 0 . Black arrows point to the areas of the paramedian infarct. The white arrow of $(f)$ points to an additional infarct of the posterior limb of the internal capsule.
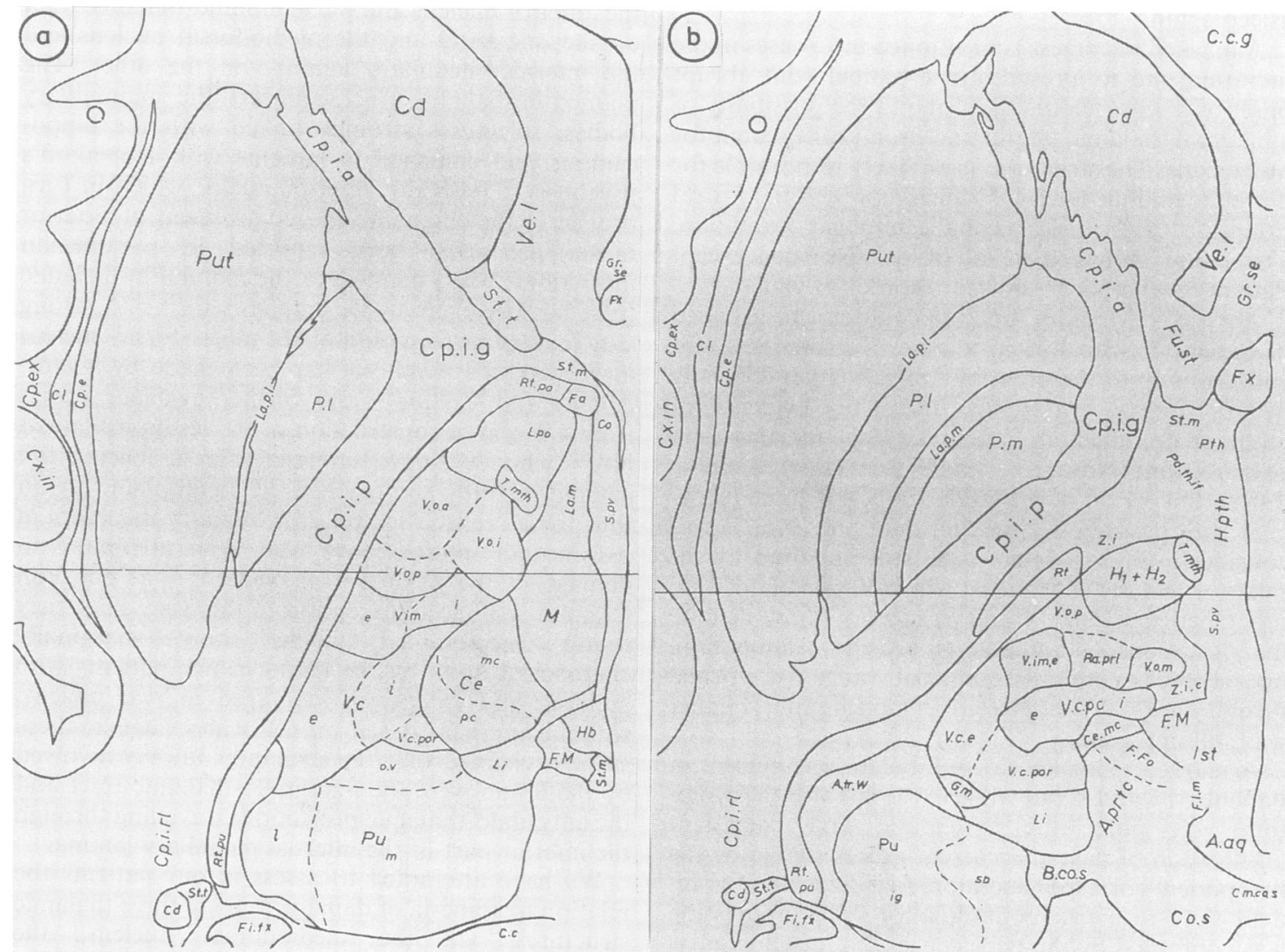

Fig 2 Maps of sections $\mathrm{Hd}+4 \cdot 0$ (a) and $\mathrm{Hd}+0 \cdot 5$ (b) of the Atlas."

Rt.po = polar reticular nucleus; Lpo = lateropolar thalamic territory; T.mth = mammillothalamic tract; La.m $=$ internal medullary lamina; $S . p v=$ midline nuclei; $V . o . i .=$ internal ventro-oral nucleus; $\boldsymbol{M}=$ mediodorsal nucleus; $H p t h=$ hypothalamus; F.l.m = medial longitudinal fasciculus; $C p . i . p=$ posterior limb of internal capsule. 
Table 3 Thalamic nuclei and structures damaged by the infarct

\begin{tabular}{|c|c|c|c|c|c|c|c|c|c|}
\hline & Rt.po & Lpo & $T . m t h$ & La.m & S.pv & V.o.i & $M$ & Hpth & F.l.m \\
\hline $\begin{array}{l}\text { Case } 1 \\
\text { Case } 2 \\
\text { Case } 3 \\
\text { Case } 4 \\
\text { Case } 5 \\
\text { Case } 6 \\
\text { Case } 7 \\
\text { Case } 8\end{array}$ & $\begin{array}{l}\mathbf{R} \\
\mathbf{R} \\
\overline{-} \\
\overline{\mathbf{R L}} \\
\overline{-} \\
\overline{\mathbf{R}}\end{array}$ & $\begin{array}{l}\mathbf{R} \\
\mathbf{R} \\
\mathbf{R} \mathbf{L} \\
\mathbf{R} \mathbf{L} \\
\mathbf{L} \\
\mathbf{R} \mathbf{L} \\
\mathbf{R}\end{array}$ & $\begin{array}{l}\text { RL } \\
\mathbf{R} \\
\mathbf{R} \mathbf{L} \\
\mathbf{R} \mathbf{L} \\
\mathbf{R L} \\
\mathbf{L} \\
\mathbf{R} \mathbf{L} \\
\mathbf{R L}\end{array}$ & $\begin{array}{l}\mathbf{R} \mathbf{L} \\
\mathbf{R} \\
\mathbf{R} \mathbf{L} \\
\mathbf{R} \mathbf{L} \\
\mathbf{L} \\
\mathbf{R} \mathbf{L} \\
\mathbf{R}\end{array}$ & $\begin{array}{l}\text { RL } \\
\text { R } \\
\text { RL } \\
\text { RL } \\
\mathbf{R L} \\
\overline{\mathbf{R L}} \\
\mathbf{R L}\end{array}$ & $\begin{array}{l}\mathbf{R L} \\
\mathbf{R L} \\
\mathbf{R} \\
\mathbf{R} \\
\mathbf{R} \\
\mathbf{R} \mathbf{L} \\
\mathbf{R} \mathbf{L} \\
\mathbf{R}\end{array}$ & $\begin{array}{l}\mathbf{R L} \\
\mathbf{L} \\
\mathbf{R L} \\
\mathbf{R L} \\
\mathbf{R L} \\
\mathbf{R L} \\
\mathbf{R L}\end{array}$ & $\begin{array}{l}\mathbf{R L} \\
\overline{\mathbf{R L}} \\
\mathbf{R L} \\
\mathbf{R L} \\
- \\
\overline{\mathbf{R L}}\end{array}$ & $\begin{array}{l}- \\
- \\
\overline{R L} \\
\overline{-} \\
\overline{R L}\end{array}$ \\
\hline
\end{tabular}

Rt.po, polar reticular nucleus; Lpo, lateropolar thalamic territory; T.mth, mammillothalamic tract; La.m, internal medullary lamina; S.pv, midline nuclei; V.o.i., internal ventro-oral nucleus; M, mediodorsal nucleus; Hpth, hypothalamus; F.l.m, medial longitudinal fasciculus.

$\mathbf{R}=$ right, $\mathbf{L}=$ left; $\mathbf{R L}=$ bilateral; $-=$ spared.

the day more than a year after the stroke. When in this state, patients could be easily awakened and engaged in conversation and some of them were also able to take mental tests, and to give coherent responses. Left alone, however, they tended to fall asleep again.

A marked sleepiness is mentioned in 15 cases in the literature and its presence in a patient with abrupt onset of disease should alert one to the possibility of a bilateral thalamic infarct and prompt the search for other signs. The structures most likely responsible for it are the midline nuclei, ${ }^{18}$ which represent the rostral extension of the mesencephalic reticular formation. They were damaged in all of our patients, except Patient 6, who never showed disorder of vigilance.

2. Amnesia Memory function could not be assessed in Patient 5, who was in a state of drowsiness and confusion up to the point of dying. Neither clinically nor on formal testing was there any evidence of amnestic decrement in Patient 2. Of the remaining six patients, four (Nos. 1, 3, 7 and 8) were clearly amnesic during the period of hospitalisation, but three recovered with passage of time and only one (No. 3) was considered 3 years later to be still impaired by his relatives and the neurologist who examined him. Two other patients (Nos. 4 and 6) did not show definite manifestations of amnesia at bedside examination, but scored in the pathological range on formal memory tests. When retested 18 months later, neither was still impaired.

A marked tendency to confabulate was present in Patients 1,7 and 8 , but while in the last two the symptom was pure, the systematic and consistent falsification of past and current events shown by the first patient corresponded more to a delusion of grandeur than to a true confabulation. This impression was confirmed by the persistence of a megalomaniac attitude at a time when amnesia had completely disappeared. By and large, an impairment of męmory function appears to be a frequent concomitant of bilateral medial thalamic damage, but it generally tends to subside with passage of time.

The thalamic structures that have been implicated in memory function belong to two discrete systems: the anterior nucleus and the mammillo-thalamic tract on the one hand and the mediodorsal nucleus and the internal medullary lamina, on the other. The mammillo-thalamic tract connects the mammillary bodies, structures strongly linked with the hippocampus and damaged in patients with Korsakoff's psychosis, ${ }^{23}$ with the anterior nuclei, which in turn project to the cingulum. No involvement of anterior nuclei has even been reported in paramedian infarctions, while damage to the mammillo-thalamic tract has been repeatedly emphasised. ${ }^{1013}$ A strong case for the participation of the mediodorsal nucleus in Korsakoff's psychosis has been made by Victor, Adams and Collins ${ }^{24}$ and further evidence comes from CT scan reconstruction of the lesion in Patient $\mathrm{NA}^{25}$ who developed amnesia after a fencing foil entered rostrally and reached the diencephalic region (but for a critique see ref 26). Memory disorders in paramedian infarcts have also been attributed to damage of the mediodorsal nuclei, ${ }^{111318}$ but Von Cramon et $\mathrm{l}^{7}$ took exception to this view since they found mediodorsal nuclei only marginally encroached upon by the lesion in five patients with amnesia and extensively damaged in two patients without amnesia. Based on CT scan evidence, these authors claimed that the structures always involved by the lesion were the mammillo-thalamic tract and the amygdalo-thalamic projections travelling through the inferior part of the internal medullary lamina.

We have attempted to assess in our patients the relation to amnesia of damage to these three thalamic structures, viz the mediodorsal nucleus, the mammillo-thalamic tract and the internal medullary lamina. 
Table 4 Damage to the structures presumed to play a role in thalamic amnesia

\begin{tabular}{|c|c|c|c|c|}
\hline Pt $N$ & $\begin{array}{l}\text { Severity of } \\
\text { amnesia }\end{array}$ & $\begin{array}{l}\text { Mediodorsal } \\
\text { nuclei }\end{array}$ & $\begin{array}{l}\text { Mammillothalamic } \\
\text { tract }\end{array}$ & $\begin{array}{l}\text { Internal medullary } \\
\text { lamina }\end{array}$ \\
\hline $\begin{array}{l}1 \\
2 \\
3 \\
4 \\
6 \\
7 \\
7 \\
8\end{array}$ & $\begin{array}{l}\mathbf{A}+ \\
\mathbf{A}- \\
\mathbf{A}+++ \\
\mathbf{A}+ \\
\mathbf{A}+ \\
\mathbf{A}++ \\
\mathbf{A}++\end{array}$ & $\begin{array}{l}\text { Partial, left } \\
\text { Partial, left } \\
\text { Partial, bilateral } \\
\text { Extensive, bilateral } \\
\text { Partial, left } \\
\text { Extensive, bilateral }\end{array}$ & $\begin{array}{l}\text { Bilateral } \\
\text { Right } \\
\text { Bilateral } \\
\text { Bilateral } \\
\text { Left } \\
\text { Bilateral } \\
\text { Bilateral }\end{array}$ & $\begin{array}{l}\text { Bilateral } \\
\text { Right } \\
\text { Bilateral } \\
\text { Left } \\
\text { Bilateral } \\
\text { Right }\end{array}$ \\
\hline
\end{tabular}

$\mathrm{A}-=$ no amnesia; $\mathbf{A}+=$ amnesia only apparent on testing; $\mathbf{A}++=$ amnesia only in the acute stage; $\mathbf{A}+++=$ long-lasting, severe amnesia.

Table 4 summarises the findings. Data of Patient 5 are omitted, because his vigilance was so impaired as to prevent memory evaluation. Our data support Von Cramon et al's ${ }^{7}$ claim that the mediodorsal nucleus plays no crucial role in amnesia. Its damage was extensive and bilateral in two patients only, while in four cases it was confined to its outermost ventrobasal part (bilaterally in one patient and unilaterally in three) and the nucleus was completely spared in the patient (No. 3) who had the most severe and longlasting memory disorder. The internal medullary lamina was apparently intact in this patient, whose infarct destroyed the mammillo-thalamic tract bilaterally. This structure was involved in all patients, but limited to the right side in the one case (No. 2), who never showed evidence of amnesia and to the left side in a patient with memory impairment only apparent on formal testing. The internal medullary lamina was affected three times bilaterally and three times unilaterally. Its apparent sparing in the severely amnestic patient casts doubt on its actual role in memory function. Thus evidence marshalled in the present study points to the mammillo-thalamic tract as the structure responsible for the memory disorders associated with medial thalamic infarcts.

No support for the thesis that paramedian thalamic infarcts are associated with dementia ${ }^{18}$ is provided by our patients' performance on the WAIS, which was well within the normal range in most cases. The two patients (Nos. 4 and 8) who scored below 90 in the acute stage, had a normal IQ three months later. One should not be deceived by the slowness of response, difficulty with concentration and apathy shown by the patients in the early stage of disease, as they reflect a disorder of vigilance or motivation rather than a true loss of intelligence.

3. Instinct and mood alterations A period of bulimia was evident in four patients (Nos. 2, 3, 4 and 8). It lasted a few days in Patient 2, two weeks in Patients 3 and 4 and was still present, though to a mild degree, three months after onset in Patient 8 . We have found in the literature no mention of this symptom, possibly because it can go unnoticed by the physician unless relatives or nurses are explicitly questioned about it. It is likely dependent upon the encroachment of the lesion on diencephalic structures.

Changes of mood were apparent in the majority of testable patients (No. 5 was too drowsy to permit assessment), and generally consisted of a mixture of irritability and apathy. A few patients were in a chronic bad mood, answered the physician's questions rudely and got angry for trivial reasons. One patient (No. 2) alternated periods of fretfulness with periods of silly cheerfulness, when she ostentatiously kissed and hugged her husband in the presence of other people and indulged in coarse and inappropriate jokes about the physicians. In Patient 1 the affective tone tended towards euphoria in agreement with the ideational contents of his thought, where boasts of wealth, power and mastery of foreign languages recurred.

4. Vertical gaze paresis was present in five patients (Nos. 1, 2, 4, 5 and 8). In Cases 1, 5 and 8, both upwards and downwards saccadic and pursuit movements were absent; Case 2 had a restricted upwards gaze and a normal downwards gaze; Case 4 had an absent upwards gaze and a restricted downwards gaze. The supranuclear nature of the disorder was demonstrated by the integrity of vertical oculocephalic movements. Involvement of the pretectal region close to the posterior commissure and in particular of the rostral interstitial nucleus of the medial longitudinal fasciculus, located above the oculomotor nuclei, is at present considered the most likely cause of Parinaud's syndrome. This region has been found damaged in seven cases of bilateral paramedian thalamopeduncular infarct 2227 showing various combinations of upward and downward gaze paresis, four of whom ${ }^{27}$ could be verified at necropsy. In our series the rostral part of the medial longitudinal fasciculus was marginally damaged in two patients (Nos. 5 and 8 ) and intact in the remaining three with vertical gaze paresis. The oculomotor disorder was thus likely due to the involvement of the frontofugal dorsothalamic 
bundle traversing the mediodorsal nucleus and the internal medullary lamina in its way to the superior colliculus $^{28}$ and possibly also of the efferents from the superior colliculus to the rostral interstitial nucleus.

\section{Concluding remarks}

The clinical picture presented by patients with bilateral medial thalamic infarcts lends itself to diagnostic errors if this aetiology is not kept in mind. The sudden onset of a stuporous or comatose state, in the absence of motor deficits, easily evokes the idea of a subarachnoid haemorrhage and this was in fact the first diagnosis entertained in some of our cases. In other patients the outstanding symptom was the alteration of behaviour, which manifested itself as disorientation to space and time, with memory loss or thought disorders, that is a picture suggestive of a metabolic or toxic encephalopathy. The symptom that is at most suggestive of the thalamo-subthalamic localisation of the lesion is vertical gaze paresis, but it was present in only five cases and can be overlooked in the early days of disease when the patient's cooperation is poor. Aphasia and hemi-inattention, which have been repeatedly reported following strokes lateralised to the left and right thalamus, respectively, were not observed either in the present series or in the great majority of comparable cases in the literature, and this points to their dependence on the involvement of other thalamic nuclei.

The distinction between polar and paramedian artery infarcts, which is predicted by anatomical studies, is often blurred by the simultaneous involvement of both territories. Although the reconstruction of lesion boundaries by means of CT scan findings has obvious limitations, the present data indicate that in seven of eight cases the infarct extended to the area of supply of the polar artery. The variability in the extension of lesion may account for some of the differences found in the clinical picture.

The prognosis of this kind of infarct is neither severe nor good: only one patient died and a certain degree of recovery occurred in the majority of those who survived. Both memory deficits and hypersomnia subsided to a considerable extent, if not completely, in the majority of patients. In addition vertical gaze paresis tended to improve and never seriously disturbed the patient's activities. Yet none of the patients who were followed-up for more than a year returned to normal behaviour: Patient 1 is still prey to his delusional fancies, Patient 2 continues to suffer from somnolence and depression, Patient 3 is profoundly amnesic, Patient 4 tends to fall asleep if he is not engaged in some activity, and Patient 6 is practically bedridden (although, probably, because of an additional disease).

This research was supported by a grant of the Ministero della Pubblica Istruzione and a CNR grant to Dr E De Renzi.

\section{References}

1 Dejerine J, Roussy G. Le syndrome thalamique. Rev Neurol (Paris) 1906;14:521-32.

2 Martin JJ. Thalamic syndromes. In: Vinken PJ, Bruyn GW, eds. Handbook of Clinical Neurology. Vol 2. Amsterdam: North Holland Publishing, 1969.

3 Percheron G. Les arteres du thalamus humain. Artere et territoire thalamiques polaires de l'artere communicante posterieure. Rev Neurol (Paris) 1976a;132: 297-308.

4 Percheron G. Les arteres du thalamus humain. Arteres et territoires thalamiques paramedians de l'artere basilaire communicante. Rev Neurol (Paris) 1976;132:309-24.

5 Percheron G. Les arteres du thalamus humain. Les arteres choroidiennes. Etude macroscopique des variations individuelles et systematisation. Rev Neurol (Paris) 1977;133:533-45.

6 Graff-Radford NR, Damasio H, Yamada T, Eslinger PJ, Damasio AR. Nonhaemorrhagic thalamic infarction. Clinical, neuropsychological and electrophysiological findings in four anatomical groups defined by computerised tomography. Brain 1985;108:485-516.

7 Von Cramon DY, Hebel N, Schuri U. A contribution to the anatomical basis of thalamic amnesia. Brain 1985;108:993-1008.

8 De Renzi E, Faglioni P, Ruggerini C. Prove di memoria verbale di impiego clinico per la diagnosi di amnesia. Archivio di Psicologia Neurologia e Psichiatria 1977;3:303-18.

9 Schaltenbrand G, Wahren W. Atlas for Stereotaxy of the Human Brain: Architectonic Organisation of the Thalamic Nuclei, by Rolf Hassler. Stuttgart: Georg Thieme Publishers, 1977.

10 Castaigne P, Lhermitte F, Buge A, Escourolle R, Hauw JJ, Lyon-Coen O. Paramedian thalamic and midbrain infarcts: clinical and neuropathological study. Ann Neurol 1981;10:127-48.

11 Mills RP, Swanson PD. Vertical oculomotor apraxia and memory loss. Ann Neurol 1978;1:149-53.

12 Halmagyi GM, Evans WA, Hallinan JM. Failure of downward gaze. Arch Neurol 1978;35:22-6.

13 Schott B, Mauguiere F, Laurent B, Serclerat O, Fisher C. L'amnesie thalamique. Rev Neurol (Paris) 1980; 136:117-30.

14 Barbizet J, Degos JD, Louarn F, Nguyen JP, Mas JL. Amnesie par lesion ischemique bi-thalamique. Rev Neurol (Paris) 1981;137:415-24.

15 Petit H, Rousseaux M, Clarisse J, Delafosse A. Troubles oculocephalomoteurs et infarctus thalamo-sousthalamique bilateral. Rev Neurol (Paris) 1981; 137:709-22.

16 Buttner-Ennever JA, Buttner U, Cohen B, Baumgartner G. Vertical gaze paralysis and the rostral interstitial nucleus of the medial longitudinal fasciculus. Brain 1982;105: 125-49.

17 Dehaene I. Bilateral thalamo-subthalamic infarction. Acta Neurol Belg 1982;82:253-61.

18 Guberman A, Stuss D. The syndrome of bilateral paramedian thalamic infarction. Neurology 1983;33:540-6.

19 Winocur G, Oxbury S, Roberts R, Agnetti V, Davis C. Amnesia in a patient with bilateral lesions to the thalamus. Neuropsychologia 1984;22:123-43. 
20 Rousseaux M, Petit H, Hache JC, Devos PH, Dubois F, Warot P. La motricite' oculaire et cephalique dans les infarctus de la region thalamique. Rev Neurol (Paris) 1985;141:391-403.

21 Swanson RA, Schmidley JW. Amnestic syndrome and vertical gaze palsy: early detection of bilateral thalamic infarction by CT and NMR. Stroke 1985; 16:823-7.

22 Wall M, Slamovits TL, Weisberg LA, Trufant SA. Vertical gaze ophthalmoplegia from infarction in the area of the posterior thalamo-subthalamic paramedian artery. Stroke 1986;17:546-55.

23 Brierley JB. Neuropathology of amnesic states. In: Whitty CWM, Zangwill OL, eds. Amnesia. London: Butterworths, 1977:199-223.

24 Victor M, Adams RD, Collins GH. The WernickeKorsakoff Syndrome (Volume 7 of the Contemporary
Neurology Series). Philadelphia: FA Davis, 1971.

25 Squire LR, Moore RY. Dorsal thalamic lesion in a noted case of chronic memory dysfunction. Ann Neurol 1979;6:503-6.

26 Weiskrantz L. On Issues and Theories of the Human Amnesic Syndrome. In: Weinberger NM, McGaugh JL, Lynch G, eds. Memory Systems of the Brain: Animal and Human Cognitive Processes. New York: The Guilford Press, 1985:380-415.

27 Pierrot-Deseilligny CH, Chain F, Gray F, Serdaru M, Escourolle R, Lhermitte F. Parinaud's syndrome: electro-oculographic and anatomical analyses of six vascular cases with deductions about vertical gaze organisation in the premotor structures. Brain 1982;105:667-96.

28 Leichnetz GR. The prefrontal cortical oculomotor trajectories in the monkey. J Neurol Sci 1981;49:387-96. 